\title{
Popular ethnomedicinal plant Alstonia scholaris induces neurotoxicity-related behavioural changes in Swiss Albino Mice
}

Yahyea Baktiar Laskar ${ }^{1}$, A.S.M Islamul Hoque Laskar ${ }^{1}$, Abu Barkat Md Gulzar ${ }^{1}$, Udaya Kumar Vandana ${ }^{1}$, Niloy Bhattacharjee ${ }^{1}$, Pranab Behari Mazumder ${ }^{1 *}$

Natural Product \& Biomedicine Research Laboratory, Department of Biotechnology, Assam University, Silchar, India.

\section{Corresponding Authors Details:}

Prof. Dr Pranab Behari Mazumder, Professor, Department of Biotechnology, Assam University, Silchar, India. E-mail: pbm.npg.lab@gmail.com, ORCID: 0000-0002-0926-6636

\begin{abstract}
:
Plants constituents are a reliable source of the remedial need of humanity for ages by being the basis of the traditional medicinal system and often serving as the prototype for designing modern medicine. Several plants are used in traditional medicine for ages without proper administration guidelines in terms of dosages. Several toxicological analyses revealed side-effects of such therapies beyond a specific dose. One such plant is Alstonia scholaris, widely used in numerous traditional medicines to treat diseases like ulcers, asthma, diabetes, etc. The present study investigated the neurotoxic effect of the plant extract through oxidative stress in Swiss albino mice. The treated mice showed anxiety, neophobic and depression-like properties compared to control mice. The biochemical parameters show an increase in Malondialdehyde (MDA) concentration while decreasing the total protein content in different brain regions of treated mice. The Glutathione Reductase (GR) activity shows an increase in treated mice compared to the control one. The study indicates that Alstonia scholaris may cause severe damage to the central nervous system when administered without a proper guideline.
\end{abstract}

Keywords: Alstonia scholaris; Neurotoxicity; in-vivo; Malondialdehyde; Glutathione Reductase. 


\section{Introduction:}

Traditional medicines that primarily include plant-based preparations are the most commonly used source of inexpensive and accessible remedies in many developing countries[1]. In developed countries, they are used as alternative medicines either with current therapies for synergistic effect or as a substitute for expensive treatments[2]. The low therapeutic index of many modern drug formulations also aided traditional medicines' popularization in treating chronic illnesses[3]. Several clinically successful plantbased compounds and their derivatives are administered directly as alternative medicine or in combinational therapies to treat life-threatening diseases like Cancer, Diabetes, Alzheimer's, etc. [4][5]. These compounds include taxols (Larotaxel, Paclitaxel, Cabazitaxel)for cancer treatment [6][7], Arteether/ Artemotil (an artemisinin derivative) as anti-malarial[8], Galantamine for Alzheimer's-related dementia[9], Apomorphine (a morphine derivative) for Parkinson's disease[10], and Tiotropium (an atropine derivative) for pulmonary diseases[11]. The toxicological limitations of such clinically administered plant-based drug formulations are well-documented and followed extensively. However, no specific toxicological guideline is followed for plant-based preparations in traditional therapies that might have serious consequence[12][13][14]. Some recent studies proposed that several extensively used herbal formulations showed nephrotoxicity, neurotoxicity, cardiotoxicity, hepatotoxicity and reproduction-related side effects when used without a proper guideline of administration[15][16][17][18].

Alstonia scholaris, or the devil tree, belonging to the plant family Apocynaceae is a tropical tree commonly found in tropical South-East Asia, including India, China, Bangladesh up to the African and Australian continent[19]. In Indian Traditional Medicinal Systems (Ayurveda, Siddha, and Unani), the plant's parts are used extensively to treat fever, chronic diarrhoea, dysentery, gout, rheumatism, skin diseases, malaria, jaundice, cancer, etc. [19][20]. In Chinese traditional medicine, the plant's parts are used to treat respiratory diseases, such as cough, asthma, phlegm, and COPD[19]. Additionally, its preparations are widely used in several countries and among several ethnic groups as a cost-effective alternative treatment for antipyretics in malaria, rheumatic pains, diabetes, and placenta expel after childbirth[19]. Although the plant's preparations are used widely in traditional therapies, some reports suggest that the 
plant's extracts may have several acute and chronic toxicity, including oral toxicity[21] and developmental toxicity[22] when used beyond a specific limit. Besides, Baliga et al. (2004) reported that high doses of Alstonia scholaris cause severe damage to all major organs of experimental rodent models[23]. The present study preliminarily evaluates the neurotoxic effect of the methanolic extract of the plant and the corresponding behavioural changes in experimental animals. The specific findings might help consider the neurotoxic side-effects while using the plant's preparations in traditional therapies and regularising standard administration doses.

\section{Methodology}

\subsection{Preparation of plant extract:}

The leaf samples were collected from different locations of the Cachar district of Assam, India. The samples were dried under shade for seven days. The plant materials were extracted by following the methods described by Bello et al.(2016)[24] with a few modifications. Briefly, the dried samples were ground to powder and loaded in a cellulose thimble for extraction using a soxhlet apparatus. The repetitive extraction was carried out at $40^{\circ} \mathrm{C}$ using methanol as a solvent until the colourless solvent was observed. The collected extract was filtered through Whatman filter paper (No. 1). Further, the filtrate was concentrated by removing the solvent using a vacuum rotary evaporator. The extracted materials were kept in a $-20^{\circ} \mathrm{C}$ refrigerator for further experiments. Later, two doses of the extract (100 and $300 \mathrm{mg} / \mathrm{ml}$ ) were prepared as a low and high dose by dissolving them in distilled water for oral administration.

\subsection{Experimental Animals:}

Twenty-one (21) Swiss albino mice, about 8-10 weeks old (weighing between 25 and 30g), were obtained from the College of Veterinary Sciences at Assam Agriculture University, Guwahati, India. The animals were acclimatized to standard laboratory conditions for seven days before commencing the experiments. They were housed in large, clean polypropylene cages in a temperature-controlled room with $12 \mathrm{hrs} \mathrm{light}$ and dark cycle, free access to water ad libitum and fed with a standard diet. Approval was obtained from the Institutional Animals Ethics Committee of Assam University, and all the ethical guidelines were 
followed strictly. After acclimatization, the animals were divided into three groups ( $n=7)$ : Group A (served as standard control, administered with distilled water for seven days.), Group B (administered with ASME low dose) and Group C (administered with ASME high dose). The two concentration of the extract dissolved in distilled water were administered via oral gavage. The experimental animals were kept under regular and individual observation for body weight changes, behavioural changes and toxicity signs for the next seven days. Upon completing the experiments, the mice were sacrificed, and the blood/tissue samples were collected for biochemical assays.

\subsection{Behavioural studies:}

\subsubsection{Elevated Plus Maze Test:}

The Elevated Plus Maze (EPM) Method is a regularly used behavioural assay for rodents that helps to estimate the anti-anxiety effects of pharmacological agents and steroid hormones[25]. The method has been employed in several recent impactful reports [26][27][28] that reflects the efficiency of the technique in accessing neurotoxicity-induced anxiety-related behaviour in rodents. The experiment was performed following the protocol described by Casarrubea et al. (2013)[29]. Briefly, the animals were transferred from the animal house to the experiment room in home-cages to minimize the transfer effect. They were acclimatized for another 30 minutes to overcome any possible visual and olfactory influences. The EPM apparatus consisted of two open arms $(16 \mathrm{~cm} \times 5 \mathrm{~cm})$ and two covered arms $(16 \mathrm{~cm} \times 5 \mathrm{~cm} \times 12 \mathrm{~cm})$. The arms extended from a central platform $(5 \mathrm{~cm} \times 5 \mathrm{~cm})$, and the maze was elevated to a height $\mathrm{of} 25 \mathrm{~cm}$ from the floor. Each animal was placed in the central platform, facing an open arm, and allowed to explore for 5 min freely. The EPM apparatus was cleaned with ethyl alcohol (10\%) after each observation to remove scent cues left from the preceding animal. The time spent by animals in the open arms, in the central platform and in the closed arms was calculated minute-by-minute and recorded for further analysis.

\subsubsection{Modified Hole Board Test:}

The Modified Hole Board Method $(\mathrm{mHB})$ is another powerful method widely accepted to measure multiple dimensions of unconditioned behaviour in rodents[30]. Recently, many researchers used this method to 
validate their findings on the neurotoxic effect of different plant infusions that alters the locomotion and exploratory behaviour of experimental animals[31][32][33]. The grey wooden $\mathrm{mHB}$ box $(60 \mathrm{~cm} \times 60 \mathrm{~cm}$ $\times 25 \mathrm{~cm}$ ) with sixteen equidistant holes $(3 \mathrm{~cm}$ in diameter) on the floor was raised $28 \mathrm{~cm}$ above the ground on a stand. Each equidistant hole was $28 \mathrm{~cm}$ from the nearest wall of the box. The box was divided into squares of $(20 \mathrm{~cm} \times 20 \mathrm{~cm})$. This experiment was performed by following the protocols described by Pyrzanowska et al. (2021)[33] with few modifications. Briefly, the experimental animal was placed in the corner facing the wall and allowed to explore for 5 minutes freely. The total number of heads-dips recorded. A mouse was considered to make a head-dip if both eyes disappeared into the hole. The box was cleaned with $10 \%$ alcohol after each observation to avoid any bias based on olfactory cues.

\subsubsection{Forced Swim Test:}

The Forced Swim test (FST) is a rodent behavioural test used to evaluate the depression-like symptoms and stress-coping behaviour in experimental animals when treated with new compounds/drugs or neurotoxic agents[34][35][36]. The FST was performed according to the method described by Tanaka et al. (2020)[37]

recently. Briefly, the individual mice were placed in a cylindrical glass container of $12 \mathrm{~cm}$ in diameter and $30 \mathrm{~cm}$ in height and left there for $5 \mathrm{~min}$. The cylinder was filled with water $\left(25 \pm 1^{\circ} \mathrm{C}\right)$ to a height of $20 \mathrm{~cm}$. The duration of swimming and immobility was recorded. Freshwater was used for each mice. A mouse was judged to be immobile when it ceased struggling and remained floating motionless in the water, making only those movements necessary to keep its head above water[38].

\subsection{Biochemical Assays:}

Following the behavioural studies, the mice were sacrificed immediately, and the brain tissues (cerebral cortex) were isolated by dissection. The tissues were washed with ice-cold saline, blot dry with filter paper, weighed and homogenized in a cool environment. The homogenates were used for the biochemical analyses. 


\subsubsection{Lipid peroxidation (LPO) Assay:}

Lipid peroxidation by reactive oxygen species (ROS) is a well-established detrimental mechanism for several acute and chronic brain disorders[39]. The thiobarbituric acid assay (TBA test) developed by Ohkawa et al. (1979)[40] is still used as a robust biochemical assay for detecting lipid peroxides in animal tissues. Thiobarbituric acid (TBA) reacted with malondialdehyde (MDA), which resulted in a colour compound. Briefly, to $0.2 \mathrm{ml}$ of the test sample, $0.2 \mathrm{ml}$ of SDS, $1.5 \mathrm{ml}$ of acetic acid and $1.5 \mathrm{ml}$ TBA was added. The mixture was made up to $4 \mathrm{ml}$ with water and then heated in a water bath at $95^{\circ} \mathrm{C}$ for 60 minutes. After cooling, $1 \mathrm{ml}$ of water and $5 \mathrm{ml}$ of $\mathrm{n}$-butanol/pyridine mixture was added and shaken vigorously. After centrifuging at $4000 \mathrm{rpm}$ for 10 minutes, the organic layer was formed, and its absorbance was measured spectrophotometrically at $532 \mathrm{~nm}$. The level of lipid peroxidation was expressed as nmoles of MDA released per gram of wet tissue. The concentration of MDA was expressed using the formula: Absorbance at $532 \mathrm{~nm} \times \mathrm{D} / \mathrm{L} \times €$, where $\mathrm{L}=$ light path $(1 \mathrm{~cm}), \mathrm{D}=$ dilution factor and, $€=$ extinction coefficient $(1.56 \times$ $105 \mathrm{M}-1 . \mathrm{cm}-1)$.

\subsubsection{Total protein estimation:}

The total protein content of the samples was assessed using Folin-Lowry's method of protein estimation[41]. The absorbance of standards was measured at $550 \mathrm{~nm}$ against the blank, and a standard curve was generated. From this standard curve, the protein concentration for samples was calculated.

\subsubsection{Glutathione reductase (GR) activity assay:}

The GR activity in the experimental tissue samples was determined spectrophotometrically at $340 \mathrm{~nm}$ by following Carlberg and Mannervik (1975) method[42]. Briefly, the GR activity was determined by measuring the oxidation of NADPH at $340 \mathrm{~nm}$ in a reaction mixture containing $1.8 \mathrm{ml}$ phosphate buffer, $300 \mu \mathrm{l}$ each of EDTA, NADPH, oxidized glutathione (GSSG) and enzyme extract. The unit of GR activity was expressed as the amount that catalyzes the consumption of $1 \mu \mathrm{mol}$ of substrate per minute, using a molar extinction coefficient of $6.2 \mathrm{mM}^{-1} \mathrm{~cm}^{-1}$ for $\mathrm{NADH} / \mathrm{NADPH}$. 


\section{Results:}

\subsection{Change in Body weights:}

Body weights of both the control and treated animals were measured on an alternative day until the experiments. The body weights of LD-treated and HD-treated animals showed a $2.58 \%$ and $0.23 \%$ increased in weight, respectively. In contrast, control animals showed a $5.18 \%$ weight gain on the $7^{\text {th }}$-day than the initial body weight (Figure 1).

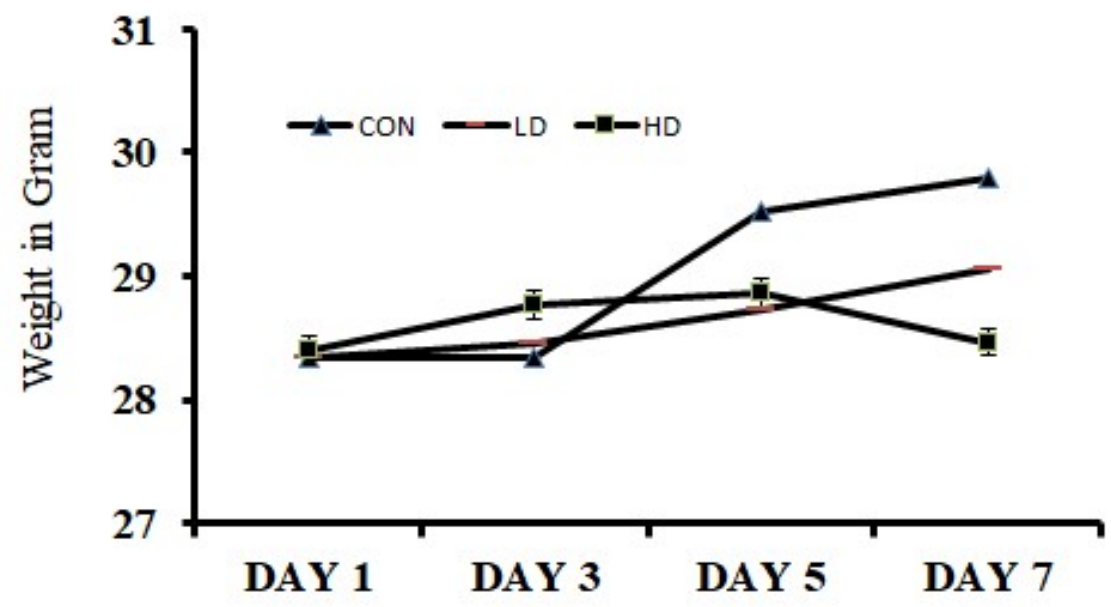

Figure 1: Effect of Alstonia scholaris Low-dose(LD) and High-dose (HD) on the body weights of the treated mice in comparison to the control $(\mathrm{CON})$ mice.

\subsection{Elevated Plus Maze Test:}

EPM test was performed to understand the variation of anxiety that occurred in different treated groups. The anxiety is estimated by the difference between the time spent in the open arm and the closed arm. More time spent in the closed arm indicates more anxiety, i.e. anxiogenic mice. The observations were crossvalidated by treating the mice with diazepam, a popular anxiolytic drug. Diazepam treatment reduced the anxiety symptoms in ASME-treated mice as the mice marked more occurrence in the open arms of the EPM apparatus. On day one, no significant change in anxiety-related behaviour was observed in any group after ASME treatment. However, after extended exposure, the treated mice showed an increase in anxiogenic behaviour than the control. On day four, the LD-treated and HD-treated mice showed a 1.3 and 1.29 fold 
increase in anxiogenic behaviour, respectively. On day seven, the anxiogenic behaviour in HD-treated mice increased significantly by 1.19 fold, whereas the LD-treated group showed only a 1.03 fold surge. The time spent (in seconds) by different groups in the closed arm and open arm of the EPM apparatus is shown in Figure 2 and Figure 3. These observations indicate that ASME could induce anxiety in rodents in a dose and duration-dependent manner.

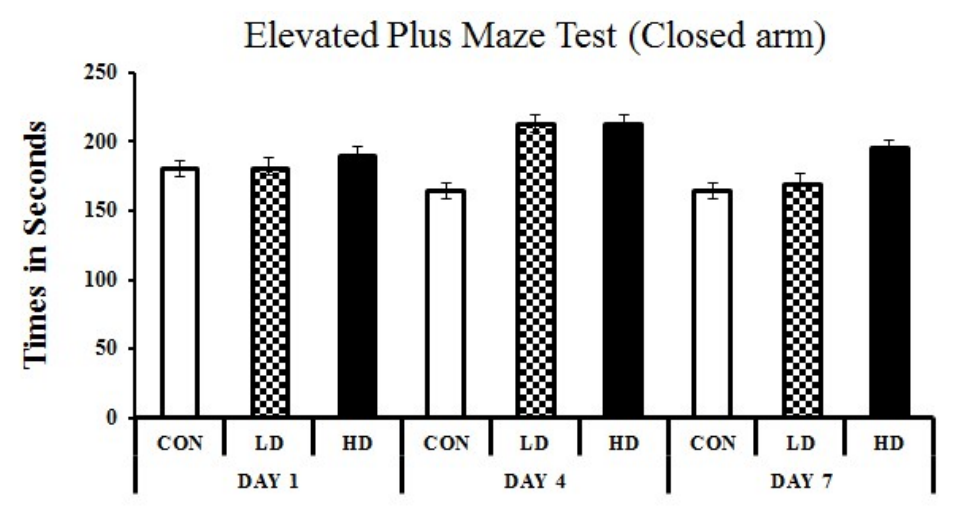

Figure 2: Showing the effect of ASME treatment on the anxiogenic behaviour of experimental animals: The time spent (in seconds) by different groups in the open arm of the EPM apparatus.

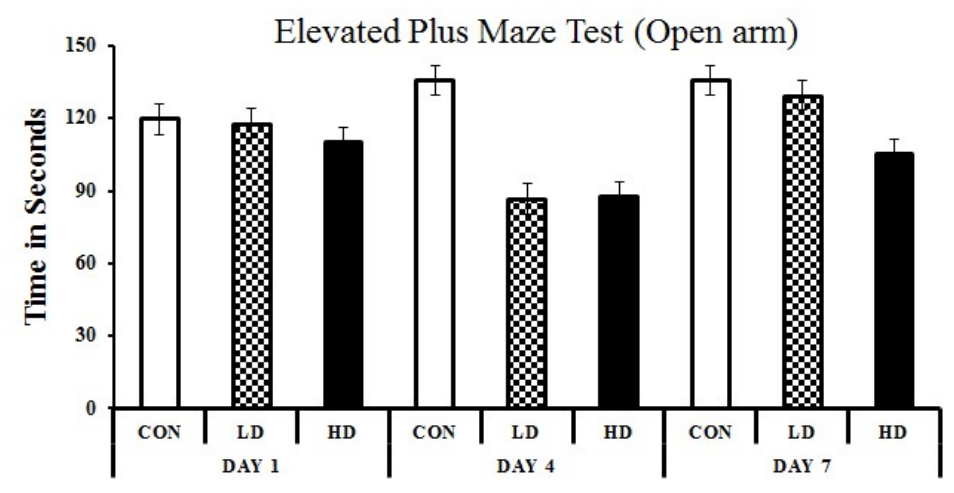

Figure 3: Showing the effect of ASME treatment on the anxiogenic behaviour of experimental animals: The time spent (in seconds) by different groups in the open arm of the EPM apparatus.

\subsection{Modified Hole Board Test:}

The Modified Hole Board (mHB) test is a measure of exploratory (neophilia/neophobic) behaviour. The exploratory behaviour (EB) was measured by the number of head-dips made by the animals into the hole when kept in a new/unknown environment. The EB of the animal varied marginally on the $1^{\text {st }}$ day of ASME exposure. However, on prolonged exposure, the mice showed signs of anxiety and reduced EB. On day 
four, the EB of LD-treated and HD-treated mice marked a $23.16 \%$ and $34.74 \%$ fall from control, respectively. The anxiety-induced decrease in EB was higher on the $7^{\text {th }}$ day as well, and the mice showed neophobic activity with 31.31\% (LD-treated) and 36.36\% (HD-treated) reduced exploratory activity compared to the control (Figure 4). However, diazepam treatment improved the exploratory behaviour in the experimental groups, indicating that anxiety caused the neophobic signs in those mice.

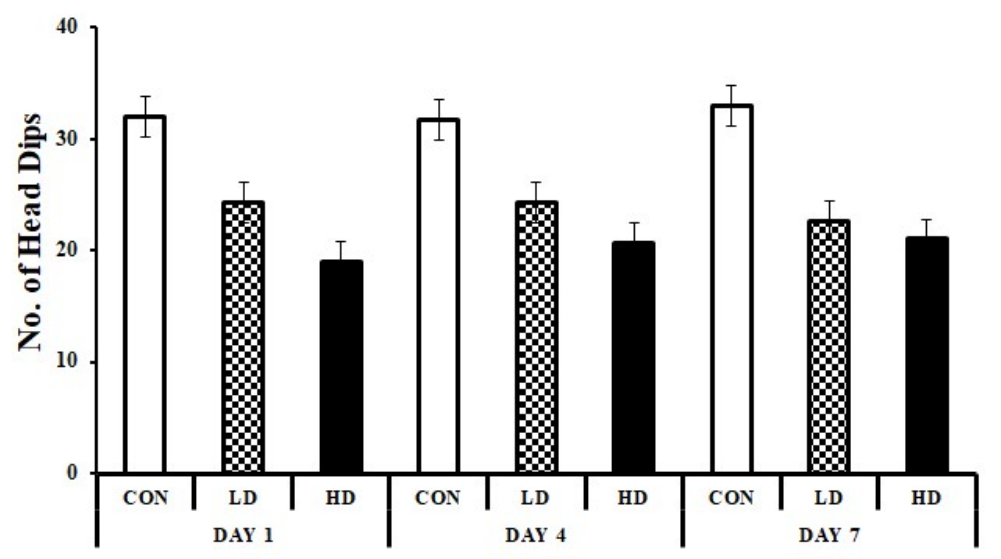

Figure 4: Showing the effect of ASME treatment on the exploratory behaviour of experimental animals: The Yaxis ressembels the no.of head-dips in 5minutes on a mHB test.

\subsection{Forced Swim Test:}

The Forced Swim Test (FST) was performed to explore the effect of ASME treatment on inducing depression-like symptoms on experimental animals. An increased immobility time in FST indicates depression signs in rodent models[43]. The test was performed on the $7^{\text {th }}$ day of the experimental setup before sacrificing the mice. The LD-treated and HD-treated mice exhibited a respective 1.85 and 2.06 fold increase in immobility and an increased floating time compared to the control group (Figure 5). Moreover, normal swimming tendency was observed in the experimental animal on treating with fluoxetine, an approved antidepressant. These observations indicate that ASME could induce depression-like symptoms in mice in a dose-dependent manner. 


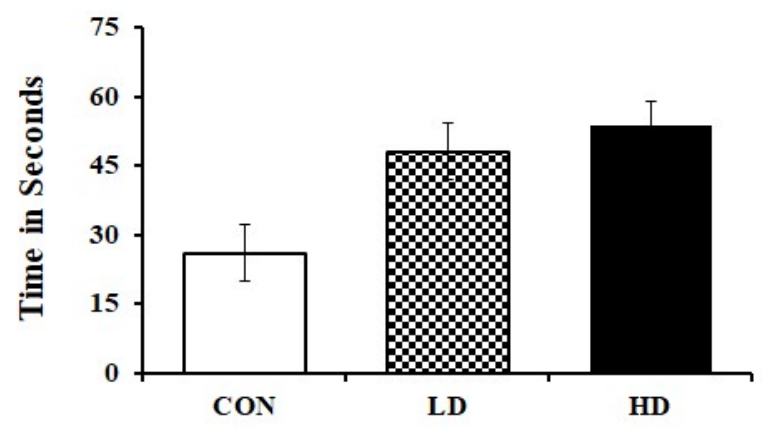

Figure 5: ASME treatment induced depression-like symptoms on experimental animals: The figure indicating the immobility time of animal in FST after treatment with low-dose and high-dose of ASME.

\subsection{Lipid Peroxidation (LPO) Assay:}

The lipid peroxidation was estimated spectrophotometrically by measuring the concentration of malondialdehyde (MDA) formed in the tissue samples. A higher value of MDA indicates elevated lipid peroxidation that leads to several chronic and acute brain ailments[44][45]. The MDA concentrations in the mice cortex tissue homogenates of the control, LD-treated and HD-treated groups were found to be $37 \pm 1.53$, $51.47 \pm 6.26$ and $53.67 \pm 1.86 \mu \mathrm{M} / \mathrm{g}$, respectively (Figure 6). The MDA concentration elevated in the LDtreated and HD-treated groups by 1.39 and 1.45 fold, respectively, compared to the control. MDA concentrations were also found to be elevated in the cerebellum tissues by 1.46 and 1.53 fold than the control. The LD and HD-treated groups exhibited $49 \pm 7.37$ and 51.6 $\pm 3.95 \mu \mathrm{M} / \mathrm{g}$ MDA, where control groups showed only 33.67 $\pm 0.88 \mu \mathrm{M}$ MDA per gram of tissue homogenate (Figure 6 ). The results indicate that ASME treatment significantly increases the lipid peroxidation in the mice brain tissues that may have resulted in anxiety and depression like symptoms in the treated groups.

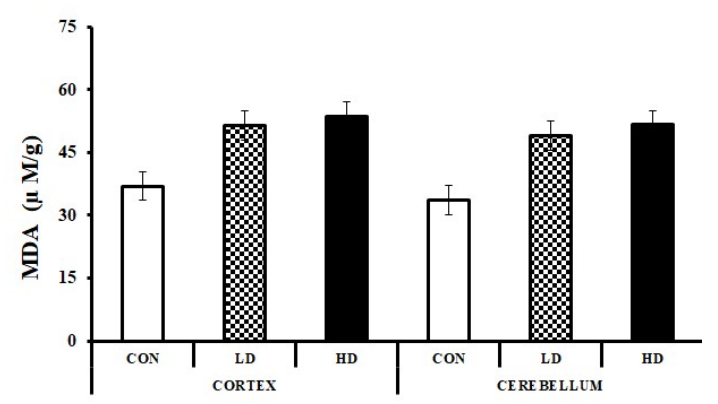

Figure 6: Effect of ASME on Malondialdehyde (MDA) level in the brain of Swiss albino mice. 


\subsection{Total protein estimation:}

The total protein content of different tissues also showed a subsequent decline from the control to the higher doses. The protein content of the cortex tissues for the control, LD and HD-treated groups were found to be $113.57 \pm 4.46,110 \pm 1.89$ and $73.57 \pm 15.67 \mathrm{mg} / \mathrm{g}$, respectively. Although the low dose of ASME declined the protein content by only $3.14 \%$ compared to the control, a high dose reduced them significantly by $35.22 \%$. In cerebellum tissues, the total protein content was reduced by $27.42 \%$ to $64.29 \pm 6.19 \mathrm{mg} / \mathrm{g}$ by the low dose of ASME and $51.61 \%$ to $42.86 \pm 3.27 \mathrm{mg} / \mathrm{g}$ by the high dose as compared to the control $(88.57 \pm 1.89 \mathrm{mg} / \mathrm{g})$. Thus, ASME treatment dramatically reduced the total protein content of the brain in a dose-dependent manner.

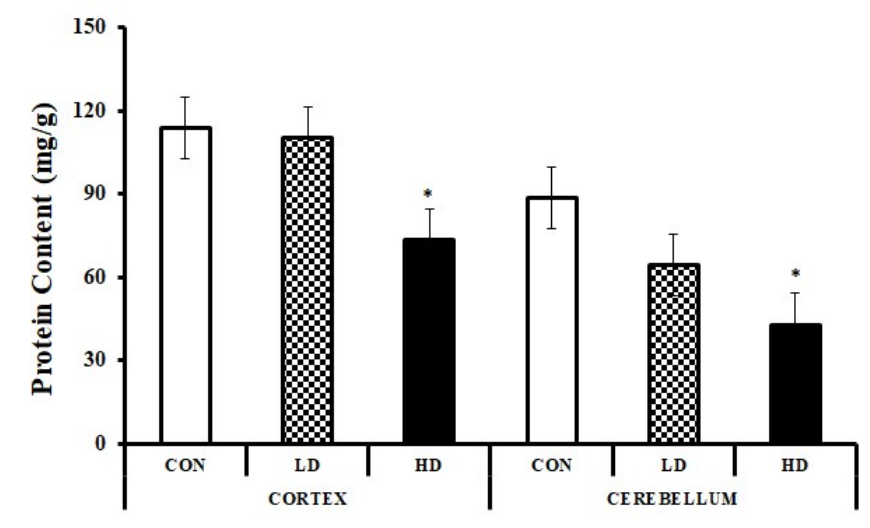

Figure 7: Effect of ASME on the total protein content of the brain of Swiss albino mice.

\subsection{Glutathione reductase (GR) activity assay:}

Glutathione reductase (GR) is an antioxidant enzyme that plays a vital role in regulating cellular redox homoeostasis by controlling the cellular level of ROS[46]. Usually, the cellular GR level increases as a response to stress induced by ROS-generating agents[47]. The GR levels in the mice cortex tissues were found to be $0.038 \pm 0.002,0.043 \pm 0.001$ and $0.052 \pm 0.004 \mu \mathrm{M} / \mathrm{min} / \mathrm{mg}$ protein, respectively for the control group, LD and HD-treated group. The values for the LD and HD-treated groups were raised by 1.13 and 1.37 fold compared to the control. The cerebellum tissues also showed similar trends of elevated GR levels with the values $0.051 \pm 0.001,0.059 \pm 0.005$ and $0.068 \pm 0.004 \mu \mathrm{M} / \mathrm{min} / \mathrm{mg}$ protein from lower dose to the 
higher dose groups (Figure 8 ). The elevated GR level might be a response to the ROS generated by ASME treatment.

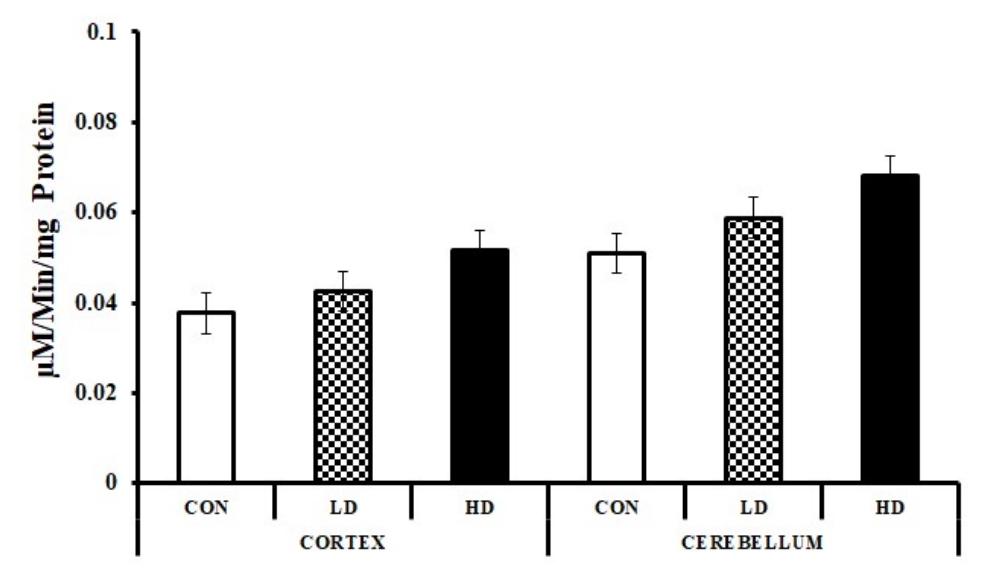

Figure 8: Effect of ASME treatment on the glutathione reductase activity in the cortex and cerebellum tissues of Swiss albino mice.

\section{Discussion:}

Traditional and complementary medicines are widely used globally, especially in India and China. The Indian Traditional Medicinal system of Ayurveda and Chinese Traditional Medicine (CTM) primarily uses plant-based preparations for treating almost every disease. Because plant-based therapies are mainly used as food or supplement, their use is not adequately regulated as the modern synthetic drugs. Ethnomedicinal research primarily reports the pharmacological activity of plants based on their ethnic or historical use but lack proper toxicological analysis of those plant extracts. The toxicological risk assessment (TRA) of any experimental chemical or drug mainly includes evaluating its toxic effect on the major organs like the brain, heart, kidneys and liver[48]. The toxicity risk associated with the central nervous system (CNS), known as neurotoxicity, is a significant step in the TRA process that determines the adverse effect of any chemical/toxin/drug on the normal functioning of the CNS[49]. Also, it is essential to determine the neurotoxic effect of a chemical because the CNS regulates many other body systems like the digestive system, the circulatory system and the immune system in a very complex way[49]. It is found that several herbal medicines possess neurotoxins resulting from misidentification of the parent plant, insufficient processing, or adulteration[16]. When administered without a proper TRA and guideline for doses, these formulations can cause severe damage to the functioning of the CNS. 
In the present study, some behavioural and biochemical parameters were observed in Swiss albino mice after treating them with $100 \mathrm{mg} / \mathrm{ml}$ (LD) and $300 \mathrm{mg} / \mathrm{ml}(\mathrm{HD})$ of Alstonia scholaris methanolic extract. The treated mice showed some fluctuation in their body weight, where the HD-treated mice showed significant weight loss compared with the control group. This significant body weight loss indicates an adverse effect of the high dose of ASME[50]. The doses also demonstrated significant behavioural changes in the treated mice. The observation in the EPM is widely used for screening potential anxiolytics and their effect on the exploration, anxiety, and motor behaviour of rodents [51]. The anxiogenic rodent tries to avoid the open arms of the maze and hides in the arms enclosed by protective walls[51]. Both the experimental groups (LD and HD-treated) showed similar anxiogenic behaviour, which was then cured by treating with diazepam. Since diazepam acts by enhancing the calming effect of gamma-aminobutyric acid (GABA) by facilitating the opening of the GABAA-activated chloride channels, it can hypothesize that ASME constituents block the action of GABA. Similar anxiety and depression-like signs were displayed by both the treated group in mHB and FST. Although the degrees of behavioural changes were consistently higher in the HD-treated group, suggesting that the neurotoxic effect of ASME is dose-dependent. The recovery of behavioural changes to normalcy after treatment with anxiolytic drug diazepam in all test cases confirms the onset of anxiety and depression-like symptoms induced by ASME doses. Similar anxiogenic results were observed by Elsas et al. (2010)[52] and Sonavane et al.(2002)[53] in male Sprague-Dawley albino rats treated with the extracts of Passiflora incarnata $\mathrm{L}$ and Myristica fragrans, respectively.

The high levels of lipid peroxidation (measured by malondialdehyde levels) and glutathione reductase in the cortex and cerebellum region of the brain indicate that ASME induces neurotoxicity through ROSgeneration. The harmful reactive oxygen species or ROS are constantly generated through normal oxidative metabolism or incomplete metabolism of foreign chemicals by the liver. ROS play a central role in the onset of several neurodegenerative diseases by causing progressive loss of neurons[54]. Lipid peroxidation in the brain is a typical response to high ROS levels that severely damage the polyunsaturated fatty acids rich neuronal membranes[55]. Malondialdehyde (MDA) is the most abundant lipid peroxidation-specific aldehyde and is highly reactive with proteins, DNA, and phospholipids, causing harmful effects[55]. The 
thiobarbituric acid (TBA) assay is performed widely to measure the red pigmentation formed by the adduct of TBA with MDA[55]. The high MDA levels estimated in the present study demonstrates oxidative stressinduced lipid peroxidation in the mice brain tissues. Consequently, high levels of antioxidant enzyme glutathione reductase (GR) were also recorded in the mice brain tissues, a detoxification mechanism against oxidative stress[56]. The study results also demonstrated that ASME extracts altered neuroprotein levels in the mouse cerebral cortex and the cerebellum, indicating that prolonged high doses may disturb neurodevelopment.

In conclusion, the study found that Alstonia scholaris extract dose-dependently induces neurotoxicity, resulting in signs of anxiety and depression in Swiss albino mice. Further, high doses of the plant extract may increase lipid peroxidation and oxidative damage to mice brain. The information obtained from this study may help to choose more appropriate test doses of Alstonia scholaris in future pharmacological studies to report results of greater clinical relevance. Lastly, caution and safety measures must be followed while using Alstonia scholaris for therapeutic or nutraceutical purposes.

\section{Funding:}

This research did not receive any specific grant from funding agencies in the public, commercial, or notfor-profit sectors.

\section{Conflict of Interest:}

All the authors declare that they have no conflict of interest regarding this manuscript.

\section{Acknowledgements:}

We want to acknowledge DBT-Electronic Library Consortium (DeLCON) for providing access to research articles and UGC-SAP for providing laboratory infrastructure. The first, second, third and fifth author gratefully acknowledges the UGC-AUS Non-NET fellowship received from University Grant Commission (India) through Assam University, Silchar, towards doctoral research. 


\section{Citations:}

[1] O. Oyebode, N.-B. Kandala, P. J. Chilton, and R. J. Lilford, "Use of traditional medicine in middleincome countries: a WHO-SAGE study," Health Policy Plan., vol. 31, no. 8, pp. 984-991, Oct. 2016, doi: 10.1093/heapol/czw022.

[2] World Health Organization, "WHO Global Report on Traditional and Complementary Medicine 2019," 2019. [Online]. Available: https://www.who.int/traditional-complementary-integrativemedicine/WhoGlobalReportOnTraditionalAndComplementaryMedicine2019.pdf?ua=1.

[3] H. Wen, H. Jung, and X. Li, "Drug Delivery Approaches in Addressing Clinical PharmacologyRelated Issues: Opportunities and Challenges,” AAPS J., vol. 17, no. 6, pp. 1327-1340, Nov. 2015, doi: 10.1208/s12248-015-9814-9.

[4] A. SAKLANI and S. KUTTY, "Plant-derived compounds in clinical trials," Drug Discov. Today, vol. 13, no. 3-4, pp. 161-171, Feb. 2008, doi: 10.1016/j.drudis.2007.10.010.

[5] O. Potterat and M. Hamburger, "Drug discovery and development with plant-derived compounds," in Natural Compounds as Drugs Volume I, Basel: Birkhäuser Basel, pp. 45-118.

[6] M. A. Ashraf, "Phytochemicals as Potential Anticancer Drugs: Time to Ponder Nature's Bounty," Biomed Res. Int., vol. 2020, pp. 1-7, Jan. 2020, doi: 10.1155/2020/8602879.

[7] A. Seca and D. Pinto, "Plant Secondary Metabolites as Anticancer Agents: Successes in Clinical Trials and Therapeutic Application," Int. J. Mol. Sci., vol. 19, no. 1, p. 263, Jan. 2018, doi: 10.3390/ijms 19010263 .

[8] B. B. Afolabi and C. A. Okoromah, "Intramuscular arteether for treating severe malaria," Cochrane Database Syst. Rev., Oct. 2004, doi: 10.1002/14651858.CD004391.pub2.

[9] S. Berkov et al., "Plant Sources of Galanthamine: Phytochemical and Biotechnological Aspects," Biotechnol. Biotechnol. Equip., vol. 23, no. 2, pp. 1170-1176, Jan. 2009, doi: 10.1080/13102818.2009.10817633.

[10] F. Carbone, A. Djamshidian, K. Seppi, and W. Poewe, “Apomorphine for Parkinson's Disease: Efficacy and Safety of Current and New Formulations," CNS Drugs, vol. 33, no. 9, pp. 905-918, Sep. 2019, doi: 10.1007/s40263-019-00661-z.

[11] A. A. Salim, Y.-W. Chin, and A. D. Kinghorn, "Drug Discovery from Plants," in Bioactive Molecules and Medicinal Plants, Berlin, Heidelberg: Springer Berlin Heidelberg, 2008, pp. 1-24.

[12] B. Schilter et al., "Guidance for the safety assessment of botanicals and botanical preparations for 
use in food and food supplements," Food Chem. Toxicol., vol. 41, no. 12, pp. 1625-1649, Dec. 2003, doi: 10.1016/S0278-6915(03)00221-7.

[13] W. M. Bandaranayake, "Quality Control, Screening, Toxicity, and Regulation of Herbal Drugs," in Modern Phytomedicine, I. Ahmad, F. Aqil, and M. Owais, Eds. Weinheim, Germany: Wiley-VCH Verlag GmbH \& Co. KGaA, 2006, pp. 25-57.

[14] D. H. Phua, A. Zosel, and K. Heard, "Dietary supplements and herbal medicine toxicities — when to anticipate them and how to manage them," Int. J. Emerg. Med., vol. 2, no. 2, pp. 69-76, Jun. 2009 , doi: 10.1007/s12245-009-0105-z.

[15] B. Yang, Y. Xie, M. Guo, M. H. Rosner, H. Yang, and C. Ronco, "Nephrotoxicity and Chinese Herbal Medicine," Clin. J. Am. Soc. Nephrol., vol. 13, no. 10, pp. 1605-1611, Oct. 2018, doi: 10.2215/CJN.11571017.

[16] E. M. Williamson, "Herbal Neurotoxicity: An Introduction to Its Occurrence and Causes," in Toxicology of Herbal Products, Cham: Springer International Publishing, 2017, pp. 345-362.

[17] P. Zhang, Y. Ye, X. Yang, and Y. Jiao, "Systematic Review on Chinese Herbal Medicine Induced Liver Injury," Evidence-Based Complement. Altern. Med., vol. 2016, pp. 1-15, 2016, doi: $10.1155 / 2016 / 3560812$.

[18] E. Stournaras, "Herbal medicine-related hepatotoxicity," World J. Hepatol., vol. 7, no. 19, p. 2189 , 2015, doi: 10.4254/wjh.v7.i19.2189.

[19] S. Akbar, "Alstonia scholaris (L.) R.Br. (Apocynaceae)," in Handbook of 200 Medicinal Plants, Cham: Springer International Publishing, 2020, pp. 225-234.

[20] M. S. Khyade, D. M. Kasote, and N. P. Vaikos, “Alstonia scholaris (L.) R. Br. and Alstonia macrophylla Wall. ex G. Don: A comparative review on traditional uses, phytochemistry and pharmacology," J. Ethnopharmacol., vol. 153, no. 1, pp. 1-18, Apr. 2014, doi: 10.1016/j.jep.2014.01.025.

[21] I. Bello et al., "Acute and Sub-Acute Toxicity Evaluation of the Methanolic Extract of Alstonia scholaris Stem Bark,” Med. Sci., vol. 4, no. 1, p. 4, Mar. 2016, doi: 10.3390/medsci4010004.

[22] G. C. Jagetia and M. S. Baliga, "Induction of developmental toxicity in mice treated withAlstonia scholaris (Sapthaparna) In utero,” Birth Defects Res. Part B Dev. Reprod. Toxicol., vol. 68, no. 6, pp. 472-478, Dec. 2003, doi: 10.1002/bdrb.10047.

[23] M. BALIGA, "The evaluation of the acute toxicity and long term safety of hydroalcoholic extract 
of Sapthaparna (Alstonia scholaris) in mice and rats," Toxicol. Lett., vol. 151, no. 2, pp. 317-326, Jul. 2004, doi: 10.1016/j.toxlet.2004.01.015.

[24] I. Bello et al., "Acute and Sub-Acute Toxicity Evaluation of the Methanolic Extract of Alstonia scholaris Stem Bark," Med. Sci., vol. 4, no. 1, p. 4, Mar. 2016, doi: 10.3390/medsci4010004.

[25] A. A. Walf and C. A. Frye, "The use of the elevated plus maze as an assay of anxiety-related behavior in rodents," Nat. Protoc., vol. 2, no. 2, pp. 322-328, Feb. 2007, doi: 10.1038/nprot.2007.44.

[26] N. B. Bertagna, P. G. C. dos Santos, R. M. Queiroz, G. J. D. Fernandes, F. C. Cruz, and T. T. Miguel, "Involvement of the ventral, but not dorsal, hippocampus in anxiety-like behaviors in mice exposed to the elevated plus maze: participation of CRF1 receptor and PKA pathway," Pharmacol. Reports, vol. 73, no. 1, pp. 57-72, Feb. 2021, doi: 10.1007/s43440-020-00182-3.

[27] N. Sotoudeh, M. R. Namavar, A. Zarifkar, and A. R. Heidarzadegan, "Age-dependent changes in the medial prefrontal cortex and medial amygdala structure, and elevated plus-maze performance in the healthy male Wistar rats," IBRO Reports, vol. 9, pp. 183-194, Dec. 2020, doi: 10.1016/j.ibror.2020.08.002.

[28] A. J. Schrader, R. M. Taylor, E. G. Lowery-Gionta, and N. L. T. Moore, "Repeated elevated plus maze trials as a measure for tracking within-subjects behavioral performance in rats (Rattus norvegicus)," PLoS One, vol. 13, no. 11, p. e0207804, Nov. 2018, doi: 10.1371/journal.pone.0207804.

[29] M. Casarrubea et al., "Temporal structure of the rat's behavior in elevated plus maze test," Behav. Brain Res., vol. 237, pp. 290-299, Jan. 2013, doi: 10.1016/j.bbr.2012.09.049.

[30] M. Labots, H. A. Van Lith, F. Ohl, and S. S. Arndt, "The Modified Hole Board - Measuring Behavior, Cognition and Social Interaction in Mice and Rats," J. Vis. Exp., no. 98, Apr. 2015, doi: $10.3791 / 52529$.

[31] A. Apu, F. Hossain, S. Bhuyan, F. Rizwan, M. Matin, and A. T. . Jamaluddin, "Study of pharmacological activities of methanol extract of Jatropha gossypifolia fruits," J. Basic Clin. Pharm., vol. 4, no. 1, p. 20, 2013, doi: 10.4103/0976-0105.109404.

[32] M. Shahed-Al-Mahmud and S. M. M. Lina, "Evaluation of sedative and anxiolytic activities of methanol extract of leaves of Persicaria hydropiper in mice," Clin. Phytoscience, vol. 3, no. 1, p. 20, Dec. 2017, doi: 10.1186/s40816-017-0056-5.

[33] J. Pyrzanowska et al., "Aspalathus linearis infusion affects hole-board test behaviour and amino 
acid concentration in the brain," Neurosci. Lett., vol. 747, p. 135680, Mar. 2021, doi: 10.1016/j.neulet.2021.135680.

[34] A. Can, D. T. Dao, M. Arad, C. E. Terrillion, S. C. Piantadosi, and T. D. Gould, "The Mouse Forced Swim Test," J. Vis. Exp., no. 58, Dec. 2011, doi: 10.3791/3638.

[35] K. G. Commons, A. B. Cholanians, J. A. Babb, and D. G. Ehlinger, "The Rodent Forced Swim Test Measures Stress-Coping Strategy, Not Depression-like Behavior," ACS Chem. Neurosci., vol. 8, no. 5, pp. 955-960, May 2017, doi: 10.1021/acschemneuro.7b00042.

[36] P. J. Fitzgerald, J. Y. Yen, and B. O. Watson, "Stress-sensitive antidepressant-like effects of ketamine in the mouse forced swim test," PLoS One, vol. 14, no. 4, p. e0215554, Apr. 2019, doi: 10.1371/journal.pone.0215554.

[37] M. Tanaka, Z. Bohár, D. Martos, G. Telegdy, and L. Vécsei, “Antidepressant-like effects of kynurenic acid in a modified forced swim test," Pharmacol. Reports, vol. 72, no. 2, pp. 449-455, Apr. 2020, doi: 10.1007/s43440-020-00067-5.

[38] B. Petit-Demouliere, F. Chenu, and M. Bourin, "Forced swimming test in mice: a review of antidepressant activity," Psychopharmacology (Berl)., vol. 177, no. 3, pp. 245-255, Jan. 2005, doi: 10.1007/s00213-004-2048-7.

[39] Y. J. Garcia, A. J. Rodríguez-Malaver, and N. Peñaloza, "Lipid peroxidation measurement by thiobarbituric acid assay in rat cerebellar slices," J. Neurosci. Methods, vol. 144, no. 1, pp. 127135, May 2005, doi: 10.1016/j.jneumeth.2004.10.018.

[40] H. Ohkawa, N. Ohishi, and K. Yagi, "Assay for lipid peroxides in animal tissues by thiobarbituric acid reaction," Anal. Biochem., vol. 95, no. 2, pp. 351-358, Jun. 1979, doi: 10.1016/00032697(79)90738-3.

[41] O. H. LOWRY, N. J. ROSEBROUGH, A. L. FARR, and R. J. RANDALL, "Protein measurement with the Folin phenol reagent.," J. Biol. Chem., vol. 193, no. 1, pp. 265-75, Nov. 1951, [Online]. Available: http://www.ncbi.nlm.nih.gov/pubmed/14907713.

[42] I. Carlberg and B. Mannervik, "Purification and characterization of the flavoenzyme glutathione reductase from rat liver.," J. Biol. Chem., vol. 250, no. 14, pp. 5475-80, Jul. 1975, [Online]. Available: http://www.ncbi.nlm.nih.gov/pubmed/237922.

[43] V. Castagné, P. Moser, S. Roux, and R. D. Porsolt, "Rodent Models of Depression: Forced Swim and Tail Suspension Behavioral Despair Tests in Rats and Mice," Curr. Protoc. Neurosci., vol. 55, no. 1, Apr. 2011, doi: 10.1002/0471142301.ns0810as55. 
[44] D. Achitei, A. Ciobica, G. Balan, E. Gologan, C. Stanciu, and G. Stefanescu, "Different Profile of Peripheral Antioxidant Enzymes and Lipid Peroxidation in Active and Non-active Inflammatory Bowel Disease Patients," Dig. Dis. Sci., vol. 58, no. 5, pp. 1244-1249, May 2013, doi: 10.1007/s10620-012-2510-z.

[45] M. Bilici, H. Efe, M. A. Köroğlu, H. A. Uydu, M. Bekaroğlu, and O. Değer, “Antioxidative enzyme activities and lipid peroxidation in major depression: alterations by antidepressant treatments," $J$. Affect. Disord., vol. 64, no. 1, pp. 43-51, Apr. 2001, doi: 10.1016/S0165-0327(00)00199-3.

[46] N. Couto, J. Wood, and J. Barber, "The role of glutathione reductase and related enzymes on cellular redox homoeostasis network," Free Radic. Biol. Med., vol. 95, pp. 27-42, Jun. 2016, doi: 10.1016/j.freeradbiomed.2016.02.028.

[47] A. Bhattacharyya, R. Chattopadhyay, S. Mitra, and S. E. Crowe, "Oxidative Stress: An Essential Factor in the Pathogenesis of Gastrointestinal Mucosal Diseases," Physiol. Rev., vol. 94, no. 2, pp. 329-354, Apr. 2014, doi: 10.1152/physrev.00040.2012.

[48] World Health Organization, "Principles and Methods for the Risk Assessment of Chemicals in Food (Public Health),” World Health Organization, 2010, pp. 3-190.

[49] P. S. Spencer and P. J. Lein, "Neurotoxicity," in Encyclopedia of Toxicology, Elsevier, 2014, pp. 489-500.

[50] A. Tahraoui, Z. H. Israili, and B. Lyoussi, "Acute and sub-chronic toxicity of a lyophilised aqueous extract of Centaurium erythraea in rodents," J. Ethnopharmacol., vol. 132, no. 1, pp. 48-55, Oct. 2010, doi: 10.1016/j.jep.2010.07.038.

[51] H. S. Foyet, D. E. Tsala, A. A. Bouba, and L. Hritcu, "Anxiolytic and Antidepressant-Like Effects of the Aqueous Extract of Alafia multiflora Stem Barks in Rodents," Adv. Pharmacol. Sci., vol. 2012, pp. 1-8, 2012, doi: 10.1155/2012/912041.

[52] S.-M. Elsas et al., "Passiflora incarnata L. (Passionflower) extracts elicit GABA currents in hippocampal neurons in vitro, and show anxiogenic and anticonvulsant effects in vivo, varying with extraction method," Phytomedicine, vol. 17, no. 12, pp. 940-949, Oct. 2010, doi: 10.1016/j.phymed.2010.03.002.

[53] G. . Sonavane, V. . Sarveiya, V. . Kasture, and S. . Kasture, "Anxiogenic activity of Myristica fragrans seeds," Pharmacol. Biochem. Behav., vol. 71, no. 1-2, pp. 239-244, Jan. 2002, doi: 10.1016/S0091-3057(01)00660-8.

[54] F. Collin, "Chemical Basis of Reactive Oxygen Species Reactivity and Involvement in 
Neurodegenerative Diseases," Int. J. Mol. Sci., vol. 20, no. 10, p. 2407, May 2019, doi: 10.3390/ijms20102407.

[55] M. Shichiri, "The role of lipid peroxidation in neurological disorders," J. Clin. Biochem. Nutr., vol. 54, no. 3, pp. 151-160, 2014, doi: 10.3164/jcbn.14-10.

[56] M. M. Djukic et al., "Protective role of glutathione reductase in paraquat induced neurotoxicity," Chem. Biol. Interact., vol. 199, no. 2, pp. 74-86, Aug. 2012, doi: 10.1016/j.cbi.2012.05.008. 